\title{
Atividade da celulase de fungos isolados do solo da Estação Ecológica de Juréia-Itatins, São Paulo, Brasil ${ }^{1}$
}

\author{
MARCELO J.S. RUEGGER ${ }^{2,3}$ e SÂMIA M. TAUK-TORNISIELO ${ }^{2}$
}

(recebido: 13 de novembro de 2002; aceito: 27 de novembro de 2003)

\begin{abstract}
Cellulase activity of fungi isolated from soil of the Ecological Station of Juréia-Itatins, São Paulo, Brazil). Eighty filamentous fungi strains isolated from soil of the Atlantic rainforest in the Banhado Grande, an Ecological Station region of Juréia-Itatins, São Paulo State, Brazil, were analysed concerning their potential to produce cellulolytic enzymes in response to the cellulose presence in the culture medium, as the only carbon source. For this purpose, a staining technique using congo red was employed and the cellulase activity on filter paper (FPase) and carboxymethylcellulose (CMCase) were measured. The fungi were differentiated regarding the activity of these enzymes, because such activity changed with the substrate type and with the methodology used. The best CMCase activity $(1.64 \mathrm{U})$ was obtained with the cultivation of Trichoderma harzianum (V) on wheat bran medium after 4 days, at $25^{\circ} \mathrm{C}$. The obtained results did not supply evidences to differentiate any strain that had better cellulase activity in relation to the others. However, they offer information necessary to evaluate whether Trichoderma strains: T. harzianum III and V, T. inhamatum I, T. longibrachiatum, T. pseudokoningii II, and T. viride I, are potentially good producers of cellulase or not.
\end{abstract}

Key words - Atlantic rainforest, cellulase activity, soil fungi

RESUMO - (Atividade da celulase de fungos isolados do solo da Estação Ecológica de Juréia-Itatins, São Paulo, Brasil). Oitenta fungos filamentosos isolados do solo da Mata Atlântica da região conhecida como Banhado Grande, Estação Ecológica de Juréia-Itatins, São Paulo, Brasil, foram analisados para avaliar seus potenciais quanto a produção de celulases em resposta à presença de celulose, como única fonte de carbono, em meio de cultura. Foi utilizada a técnica de coloração com vermelho congo e determinada a atividades da celulase em papel de filtro (FPase) e em carboximetilcelulose (CMCase). Os fungos foram diferenciados quanto à atividade dessas enzimas, pois tais atividades variaram em relação ao tipo de substrato e à metodologia aqui utilizados. A melhor atividade CMCase (1,64 U) foi obtida com o cultivo de Trichoderma harzianum (V) em meio de farelo de trigo após cultivo por 4 dias, a $25^{\circ} \mathrm{C}$. Os resultados obtidos não forneceram evidências para diferenciar qualquer linhagem que tivesse melhor atividade da celulase em relação às demais. Contudo, sugerem que estudos mais detalhados com as linhagens de Trichoderma: T. harzianum III e V, T. inhamatum I, T. longibrachiatum, T. pseudokoningii II e T. viride I, serão necessários para avaliar se estas são potencialmente boas produtoras de celulase, sob condições adequadas de cultivo.

Palavras-chave - atividade da celulase, fungos de solo, Mata Atlântica

\section{Introdução}

Na região do Banhado Grande, Estação Ecológica de Juréia-Itatins (EEJI), SP, Brasil, foram realizados estudos sobre fungos filamentosos de solo e da água (Attili 1994, Garlipp 1995, Grandi \& Attili 1996, Prada \& Pagnocca 1997), leveduras (Pinto 1999) e mais especificamente de Aphyllophorales (Tauk-Tornisielo et al. 2000) em diferentes áreas. Esses estudos contribuíram para melhor conhecimento da diversidade da micota nativa dessa região, que possui Mata Atlântica ainda pouco alterada pela ação antrópica.

Em geral, os fungos que decompõem substâncias celulósicas ocorrem no solo, colonizando vegetais,

1. Parte da tese de doutorado do primeiro autor.

2. Universidade Estadual Paulista, Centro de Estudos Ambientais, Av. 24-A, 1515, 13506-900 Rio Claro, SP, Brasil.

3. Autor para correspondência: mruegger@hotmail.com suas raízes e resíduos, com importante função de reciclagem de nutrientes. A atividade fúngica depende do conteúdo de matéria orgânica no solo, a qual determina sobremaneira a ocorrência e a distribuição desses organismos. O conhecimento da micobiota do solo, além de fundamental para o levantamento taxonômico das populações que ali se encontram, pode levar ao descobrimento de processos metabólicos utilizados por estes organismos tornandose importantes para as interações ambientais e em aplicações biotecnológicas.

A celulose, dentre os materiais naturais, é o biopolímero mais abundante do mundo (Bayer \& Lamed 1992) e pode ser hidrolisada, com ácidos, a glicose. A degradação microbiana da celulose é total e específica e tem estimulado o uso dos processos de fermentações celulolíticas pelo homem. Na natureza, esses processos representam a maior fonte de carbono para o solo (Lynch et al. 1981). 
A hidrólise da celulose por celulases resulta na produção final de glicose. Estas, porém, por serem proteínas, não conseguem penetrar com facilidade a barreira da lignina das células vegetais e, dessa forma, o difícil acesso destas enzimas às fibras de celulose constitui o principal problema para desencadeamento desse processo de degradação (Thiemann et al. 1980).

$\mathrm{Na}$ natureza, existe uma grande variedade de microrganismos que produzem celulases; apenas alguns são conhecidos como verdadeiros celulolíticos, isto é, são capazes de degradar a celulose natural. Em condições laboratoriais, algodão e papel de filtro, dentre outros, são usados como substratos indutores para a produção de exo-glicosidases e para medir a atividade do complexo celulolítico total (Robson \& Chambliss 1989).

Na indústria alimentícia, as celulases são usadas em vários processos, principalmente, na extração de: componentes do chá verde, proteína de soja, óleos essenciais, aromatizantes e do amido da batata doce. Essas enzimas participam, ainda, dos processos de produção do vinagre de laranja e do ágar e na extração e clarificação de sucos de frutas cítricas (Orberg 1981).

O objetivo deste estudo foi avaliar a atividade da celulase extracelular utilizando fungos filamentosos isolados de solo da região do Banhado Grande, na EEJI, comparando-se os cultivos em meio sintético com carboximetilcelulose, em caldo sintético contendo papel de filtro e em meio de farelo de trigo.

\section{Material e métodos}

Foram estudadas 80 linhagens de fungos isoladas por Garlipp (1995) do solo da região do Banhado Grande, na EEJI, SP, constantes da tabela 1. Os fungos, distribuídos em 19 gêneros e 47 espécies foram conservados em ágar extrato de malte (glicose: 20,0 g.L $\mathrm{L}^{-1}$; peptona: $1,0 \mathrm{~g} . \mathrm{L}^{-1}$; extrato de malte: 20,0 g.L $\mathrm{L}^{-1}$; ágar: 20,0 g. $\mathrm{L}^{-1}$ ) a $4^{\circ} \mathrm{C}$, no laboratório do Centro de Estudos Ambientais, CEA - UNESP, Rio Claro e repicados periodicamente. Todos os ensaios foram realizados em duplicata.

As linhagens foram cultivadas em meio sintético com carboximetilcelulose (CMC) como única fonte de carbono $\left(\mathrm{NaNO}_{3}: 3,0\right.$ g.L. ${ }^{-1} ; \mathrm{K}_{2} \mathrm{HPO}_{4}: 1,0$ g.L.- $\mathrm{LgSO}_{4}: 0,5$ g.L $\mathrm{L}^{-1} ; \mathrm{KCl}$ : 0,5 g.L $\mathrm{L}^{-1} ; \mathrm{FeSO}_{4} \cdot 7 \mathrm{H}_{2} \mathrm{O}: 10,0 \mathrm{mg} . \mathrm{L}^{-1} ; \mathrm{CMC}: 10,0$ g.L $\mathrm{L}^{-1}$; ágar: 20,0 g. $\left.\mathrm{L}^{-1}\right)$ e somente aquelas que não cresceram nesse meio (tabela 2) foram cultivadas em ágar carboximetilcelulose $\left(\mathrm{KH}_{2} \mathrm{PO}_{4}: 1,0\right.$ g.L $\mathrm{L}^{-1} ;\left(\mathrm{NH}_{4}\right)_{2} \mathrm{SO}_{4}: 0,5$ g.L $\mathrm{L}^{-1}$; asparagina: 0,5 g... $\mathrm{L}^{-1}$; $\mathrm{KCl}: 0,5$ g.L.-1 $; \mathrm{MgSO}_{4} .7 \mathrm{H}_{2} \mathrm{O}: 0,2$ g.L $\mathrm{L}^{-1} ; \mathrm{CaCl}_{2}: 0,1$ g.L.- $\mathrm{L}^{-1}$ extrato de leveduras: 0,5 g.L $\mathrm{L}^{-1}$; CMC: 10,0 g.L $\mathrm{L}^{-1}$; ágar: 20,0 g.L $\left.\mathrm{L}^{-1}\right)$. Os inóculos foram obtidos com agulha no centro de placas de Petri. Estas foram incubadas por 4 dias a $28^{\circ} \mathrm{C}$ e em seguida submetidas a choque térmico por $16 \mathrm{~h}$ a $50{ }^{\circ} \mathrm{C}$. Após esse período, foram adicionados $10 \mathrm{~mL}$ de solução corante de vermelho congo (2,5 g.L $\left.\mathrm{L}^{-1}\right)$ em tampão Tris $\mathrm{HCl} 0,1 \mathrm{M}, \mathrm{pH} 8,0$. Após 30 min a solução foi descartada e as culturas foram lavadas com $5 \mathrm{~mL}$ de solução de $\mathrm{NaCl}$ 0,5 M neste mesmo tampão. Os diâmetros das colônias e dos halos produzidos foram medidos com paquímetro (Nogueira \& Cavalcanti 1996).

Em seguida, as linhagens foram caracterizadas quanto à atividade da celulase utilizando-se papel de filtro (FPase). $\mathrm{O}$ ensaio foi realizado em tubos de vidro de $15 \mathrm{~cm}$ de altura, em duplicata, contendo uma fita de papel de filtro Whatman n.1, de $10 \mathrm{~cm}^{2}$, como única fonte de carbono e $10 \mathrm{~mL}$ de caldo sintético $\left(\mathrm{NaNO}_{3}: 3,0\right.$ g.L. ${ }^{-1} ; \mathrm{K}_{2} \mathrm{HPO}_{4}: 1,0$ g.L $\mathrm{L}^{-1} ; \mathrm{MgSO}_{4}$ : 0,5 g.L $\mathrm{L}^{-1} ; \mathrm{KCl}: 0,5 \mathrm{~g} . \mathrm{L}^{-1}$ e FeSO${ }_{4} \cdot 7 \mathrm{H}_{2} \mathrm{O}: 10,0 \mathrm{mg} \cdot \mathrm{L}^{-1}$, pH 5,0 ), cobrindo $2 / 3$ das fitas. Os tubos, esterilizados, foram inoculados com uma alçada de esporos dos respectivos fungos e incubados por 14 dias a $28^{\circ} \mathrm{C}$. A atividade da celulase em papel de filtro foi determinada no caldo de cultivo obtido no final da incubação, usando-se uma fita de papel de filtro de $6 \mathrm{~cm}^{2}$ em um tubo de ensaio contendo $0,5 \mathrm{~mL}$ do caldo e 1,0 mL de tampão acetato de sódio $50 \mathrm{mM}, \mathrm{pH}$ 5,0. Após incubação por $60 \min$ a $50^{\circ} \mathrm{C}$, a reação foi interrompida pela adição de $1 \mathrm{~mL}$ do reagente de Sumner (ácido 3,5 dinitro salicílico: 10,0 g.L $\mathrm{L}^{-1}$; NaOH: 16,0 g.L.-1; tartarato duplo de sódio e potássio: $300,0 \mathrm{~g} . \mathrm{L}^{-1}$ ). Para desenvolvimento da cor, os tubos foram aquecidos por $5 \mathrm{~min}$ em banho de água fervente. Os açúcares redutores foram determinados em espectrofotômetro, utilizando-se comprimento de onda $(\lambda)$ de $540 \mathrm{~nm}$. As leituras foram comparadas com o tubo do branco do ensaio, obtido nas mesmas condições, contudo, sem inóculo (Attili 1994).

Além das técnicas citadas, observou-se o potencial dos fungos quanto à atividade da celulase em meio de farelo de trigo. Para tanto, frascos Erlenmeyer de $125 \mathrm{~mL}$ contendo farelo de trigo (farelo de trigo: 5,0 g; água de torneira: $5,0 \mathrm{~mL}$ ) foram inoculados com $1 \mathrm{~mL}$ de uma suspensão de $1.10^{7}$ esporos $\mathrm{mL}^{-1} \mathrm{em}$ solução de Tween $80\left(1,0\right.$ g.. $\left.\mathrm{L}^{-1}\right)$. Os frascos permaneceram incubados por 4 dias a $25{ }^{\circ} \mathrm{C}$. Após este período, o extrato enzimático bruto foi obtido pela adição de $30 \mathrm{~mL}$ de água destilada a $4{ }^{\circ} \mathrm{C}$ nos frascos. Os substratos foram agitados com espátula e permaneceram em repouso por $3 \mathrm{~h} \mathrm{a} 4^{\circ} \mathrm{C}$. O sobrenadante foi separado através de filtração em gaze e algodão, permanecendo congelado até o momento da análise em frascos de vidro tampados e previamente rotulados. Os cultivos foram realizados em duplicata.

Para determinar a atividade CMCase (endoglucanase) utilizou-se tubo de ensaio onde foram adicionados $50 \mathrm{mg}$ de CMC e 4,9 mL de tampão acetato de sódio $50 \mathrm{mM}$, pH 5,0. Após equilíbrio térmico em banho-maria por $5 \mathrm{~min}$ a $50^{\circ} \mathrm{C}$, adicionou-se $0,1 \mathrm{~mL}$ do filtrado da cultura conservado em suporte com gelo. $\mathrm{O}$ tubo foi agitado e $1,0 \mathrm{~mL}$ (branco), foi transferido e adicionado a um tubo de centrífuga contendo $1,0 \mathrm{~mL}$ do reagente de Sumner. Os tubos foram agitados a cada 5 minutos. Amostras de 1,0 mL, após 30 e $60 \mathrm{~min}$, foram coletadas procedendo de modo idêntico ao anteriormente citado. Todos os tubos foram centrifugados por $8 \mathrm{~min}$ a 
4.200 rpm e os sobrenadantes transferidos para tubos de ensaio previamente rotulados, os quais permaneceram por 5 min em banho-maria de água fervente para desenvolver a cor, sendo resfriados em banho de água fria e acrescentando-se $10 \mathrm{~mL}$ de água destilada. Essa solução foi homogeneizada e a leitura da absorbância em $\lambda$ de $540 \mathrm{~nm}$ foi determinada contra o branco (Rodrigues 1987). Uma unidade de atividade enzimática (U) foi definida como a quantidade de enzima necessária para produzir $1 \mathrm{mmol}$ de glicose $\mathrm{mL}^{-1}$ $\min ^{-1}$ nas condições do ensaio $\left(\mathrm{U}=\mu \mathrm{mol} \mathrm{mL} \mathrm{min}^{-1} \mathrm{~min}^{-1}\right.$.

\section{Resultados e Discussão}

A tabela 1 apresenta os resultados obtidos após o cultivo dos fungos em meio sintético contendo CMC como única fonte de carbono. Destaca-se que, inicialmente, a incubação das culturas a $50^{\circ} \mathrm{C}$ apresentou duplo efeito na formação da zona de degradação da celulose. Primeiro, por permitir uma hidrólise mais rápida da celulose, assegurando que apenas as celulases

Tabela 1. Atividade da celulase de fungos filamentosos isolados do solo da região do Banhado Grande, Estação Ecológica de Juréia-Itatins, SP, cultivados em meio sintético com carboximetilcelulose por 4 dias a $28^{\circ} \mathrm{C}$. $\varnothing \mathrm{c}=$ diâmetro da colônia (mm); $\varnothing \mathrm{h}=$ diâmetro do halo $(\mathrm{mm}) ; \mathrm{Ie}=$ índice enzimático; $\mathrm{nc}=$ não cresceu; $(-)$ = não produziu halo.

Table 1. Cellulase activity of filamentous fungi isolated from soil of the Banhado Grande region, Ecological Station of JuréiaItatins, SP, cultivated on sintetic medium with carboxymethylcellulose for 4 days at $28^{\circ} \mathrm{C} . \varnothing \mathrm{c}=$ colony diameter $(\mathrm{mm}) ; \varnothing \mathrm{h}=\mathrm{halo}$ diameter $(\mathrm{mm})$; Ie = enzymatic index; $\mathrm{nc}=$ without growth; $(-)=$ without halo production.

\begin{tabular}{|c|c|c|c|}
\hline Fungos & $\varnothing c$ & $\varnothing \mathrm{h}$ & Íe \\
\hline Aspergillus niger & 29 & 42 & 1,4 \\
\hline Aspergillus wentii & 6 & 11 & 1,8 \\
\hline Aspergillus sp. & 1 & - & - \\
\hline Chalara paradoxa & 50 & 60 & 1,2 \\
\hline Chaunopycnis alba & nc & & \\
\hline Chloridium virescens I & 3 & - & - \\
\hline Chloridium virescens II & 1 & - & - \\
\hline Cladosporium cladosporioides & 1 & - & - \\
\hline Colletotrichum sp. & nc & & \\
\hline Cylindrocladium clavatum & 10 & 16 & 1,6 \\
\hline Doratomyces stemonitis & nc & & \\
\hline Gliocephalotrichum simplex & 30 & - & - \\
\hline Gliocladium nigrovirens & nc & & \\
\hline Gliocladium roseum $\mathrm{I}$ & nc & & \\
\hline Gliocladium roseum II & nc & & \\
\hline Metarhizium anisopliae & nc & & \\
\hline Mucor hiemalis & 80 & - & - \\
\hline Myrothecium roridum I & nc & & \\
\hline Myrothecium roridum II & 6 & 10 & 1,7 \\
\hline Myrothecium roridum III & nc & & \\
\hline Paecilomyces carneus I & nc & & \\
\hline Paecilomyces carneus II & nc & & \\
\hline Paecilomyces carneus III & 3 & - & - \\
\hline Penicillium aculeatum & 2 & - & - \\
\hline Penicillium citrinum I & 10 & 28 & 2,8 \\
\hline Penicillium citrinum II & 12 & 20 & 1,7 \\
\hline Penicillium corylophilum & 10 & 20 & 2,0 \\
\hline Penicillium decumbens & 20 & - & - \\
\hline Penicillium fellutanum I & 20 & - & - \\
\hline Penicillium fellutanum II & nc & & \\
\hline Penicillium funiculosum & 7 & - & - \\
\hline Penicillium glabrum I & 5 & 13 & 2,6 \\
\hline Penicillium glabrum II & 3 & 15 & 5,0 \\
\hline Penicillium herquei & 2 & 12 & 6,0 \\
\hline
\end{tabular}

\begin{tabular}{|c|c|c|c|}
\hline Fungos & $\varnothing c$ & $\varnothing \mathrm{h}$ & Íe \\
\hline Penicillium janthinellum & 14 & 27 & 1,9 \\
\hline Penicillium miczynskii & 1 & 5 & 5,0 \\
\hline Penicillium nigricans I & 12 & 25 & 2,1 \\
\hline Penicillium nigricans II & 11 & 21 & 1,9 \\
\hline Penicillium nigricans III & 10 & 20 & 2,0 \\
\hline Penicillium oxalicum & 4 & 16 & 4,0 \\
\hline Penicillium purpurogenum I & 6 & - & - \\
\hline Penicillium purpurogenum II & 8 & - & - \\
\hline Penicillium purpurogenum III & 5 & - & - \\
\hline Penicillium rugulosum & 5 & - & - \\
\hline Penicillium sclerotiorum I & 11 & 15 & 1,4 \\
\hline Penicillium sclerotiorum II & 10 & 16 & 1,6 \\
\hline Penicillium sclerotiorum III & 5 & 13 & 2,6 \\
\hline Penicillium simplicissimum I & 8 & 21 & 2,6 \\
\hline Penicillium simplicissimum II & 16 & 22 & 1,4 \\
\hline Penicillium simplicissimum III & nc & & \\
\hline Penicillium simplicissimum IV & 18 & 22 & 1,2 \\
\hline Penicillium simplicissimum $\mathrm{V}$ & 18 & 26 & 1,4 \\
\hline Penicillium spinulosum I & 6 & 10 & 1,7 \\
\hline Penicillium spinulosum II & 2 & 3 & 1,5 \\
\hline Penicillium variabile I & 6 & 11 & 1,8 \\
\hline Penicillium variabile II & 6 & 11 & 1,8 \\
\hline Penicillium verruculosum I & 12 & 18 & 1,5 \\
\hline Penicillium verruculosum II & 1 & 5 & 5,0 \\
\hline Penicillium sp. & 12 & 20 & 1,7 \\
\hline Pestalotiopsis pauciseta & nc & & \\
\hline Scopulariopsis carbonaria & nc & & \\
\hline Trichoderma hamatum I & 2 & 12 & 6,0 \\
\hline Trichoderma hamatum II & 1 & 2 & 2,0 \\
\hline Trichoderma harzianum I & 73 & - & - \\
\hline Trichoderma harzianum II & 67 & 72 & 1,1 \\
\hline Trichoderma harzianum III & 68 & - & $\begin{array}{l}\text { - } \\
\text { tinuc }\end{array}$ \\
\hline
\end{tabular}


continuação

\begin{tabular}{lrcc}
\hline Fungos & $\varnothing \mathrm{c}$ & $\varnothing \mathrm{h}$ & Íe \\
\hline Trichoderma harzianum IV & 21 & - & - \\
Trichoderma harzianum V & 90 & - & - \\
Trichoderma harzianum VI & 6 & 24 & 4,0 \\
Trichoderma inhamatum I & 55 & - & - \\
Trichoderma inhamatum II & 64 & - & - \\
Trichoderma koningii I & 62 & - & - \\
Trichoderma koningii II & 90 & - & -
\end{tabular}

\begin{tabular}{lccc}
\hline Fungos & $\varnothing \mathrm{c}$ & $\varnothing \mathrm{h}$ & Í \\
\hline Trichoderma koningii III & 51 & - & - \\
Trichoderma longibrachiatum & 66 & - & - \\
Trichoderma pseudokoningii I & 62 & - & - \\
Trichoderma pseudokoningii II & 80 & - & - \\
Trichoderma viride I & 68 & - & - \\
Trichoderma viride II & 70 & - & - \\
Verticillium lecanii & 3 & 9 & 3,0 \\
\hline
\end{tabular}

termoestáveis fossem selecionadas. E segundo, por acarretar inibição no crescimento dos fungos ou morte dos mesmos (Montenecourt \& Eveleigh 1977). Este último efeito foi constatado, pois os resultados demonstraram que não houve alterações nos valores entre os diâmetros das colônias medidos antes e após o choque térmico.

A zona mais clara ao redor das colônias, correspondente ao halo indicador da degradação da CMC, foi observada em 36 linhagens, ou seja, $45 \%$ dos fungos estudados. Procurando-se comparar essas linhagens, foi estabelecido um índice enzimático e por meio deste observou-se que algumas colônias com pouco crescimento apresentaram os maiores índices enzimáticos, como Penicillium herquei e Trichoderma hamatum I (diâmetro da colônia $=2 \mathrm{~mm}$, índice $=6,0$ ), Penicillium miczynskii e Penicillium verruculosum II (diâmetro da colônia $=1 \mathrm{~mm}$, índice $=5,0$ ) e Penicillium glabrum II (diâmetro da colônia $=3 \mathrm{~mm}$, índice $=5,0$ ).

Resultado semelhante foi observado em 48 linhagens de fungos isolados de aveia industrializada, que tiveram colônias de menor diâmetro e maiores valores de atividade da celulase (Nogueira \& Cavalcanti 1996). Pode-se concluir que o valor do índice enzimático neste estudo não foi um parâmetro adequado de avaliação na tentativa de comparar atividades entre diferentes linhagens. Esse índice pode ser utilizado, entretanto, como uma medida útil para selecionar linhagens dentro de uma mesma espécie ou como um parâmetro simples e rápido para selecionar mutantes, o que foi verificado com sucesso em linhagens de bactérias (Teather \& Wood 1982).

O halo indicador da degradação da CMC não foi observado em 29 linhagens ( $\cong 36 \%$ ), incluindo 14 linhagens do gênero Trichoderma, considerado como fonte de celulases (Feldman et al. 1988, Galliano et al. 1988). A visualização do halo depende de vários fatores, além da composição do meio de cultura. Algumas substâncias químicas do meio de cultura podem interferir no corante proporcionando resultados falso-positivos, ou ainda provocar sua precipitação ou inibir a ligação deste aos polissacarídeos (Neirotti \& Azevedo 1988).

As outras 15 linhagens ( $19 \%$ ) estudadas não cresceram nas condições deste experimento. Contudo, quando cultivadas em ágar carboximetilcelulose apresentaram crescimento e, dentre estas, 11 apresentaram halo ao redor das colônias (tabela 2). Esse resultado ressaltou a importância do controle dos fatores ambientais de crescimento, como a presença de

Tabela 2. Atividade da celulase de fungos filamentosos isolados da Estação Ecológica de Juréia-Itatins, SP, cultivados em ágar carboximetilcelulose por 4 dias a $28^{\circ} \mathrm{C}$. $\varnothing \mathrm{c}=$ diâmetro da colônia $(\mathrm{mm}) ; \varnothing \mathrm{h}=$ diâmetro do halo $(\mathrm{mm})$; Ie = índice enzimático; ( - ) = não produziu halo.

Table 2. Cellulase activity of filamentous fungi isolated from Ecological Station of Juréia-Itatins, SP, cultivated on carboxymethylcellulose agar medium for 4 days at $28{ }^{\circ} \mathrm{C}$. $\varnothing_{\mathrm{c}}=$ colony diameter $(\mathrm{mm}) ; \varnothing_{\mathrm{h}}=$ halo diameter $(\mathrm{mm})$; Ie = enzymatic index; $(-)=$ without halo production.

\begin{tabular}{lrcc}
\hline Fungos & $\varnothing \mathrm{c}$ & $\varnothing \mathrm{h}$ & $\mathrm{Ie}$ \\
\hline Chaunopycnis alba & 6 & - & - \\
Colletotrichum sp & 24 & 33 & 1,4 \\
Doratomyces stemonitis & 7 & 12 & 1,7 \\
Gliocladium nigrovirens & 8 & 18 & 2,3 \\
Gliocladium roseum I & 26 & 40 & 1,5 \\
Gliocladium roseum II & 18 & 26 & 1,4 \\
Metarhizium anisopliae & 13 & - & - \\
Myrothecium roridum I & 14 & - & - \\
Myrothecium roridum III & 14 & - & - \\
Paecilomyces carneus I & 12 & 26 & 2,2 \\
Paecilomyces carneus II & 10 & 12 & 1,2 \\
Penicillium fellutanum II & 9 & 16 & 1,8 \\
Penicillium simplicissimum III & 8 & 17 & 2,1 \\
Pestalotiopsis pauciseta & 36 & 52 & 1,4 \\
Scopulariopsis carbonaria & 9 & 10 & 1,1 \\
\hline
\end{tabular}


aminoácidos e/ou fontes orgânicas de nitrogênio, além de outros. A utilização do ágar carboximetilcelulose contendo baixas concentrações de asparagina e extrato de leveduras foi fator importante para a produção da celulase nesses fungos.
Na tabela 3 são apresentados os resultados das atividades da celulase em papel de filtro (FPase) após 14 dias a $28^{\circ} \mathrm{C}$, e aqueles realizados em meio de farelo de trigo (CMCase) após 4 dias a $25^{\circ} \mathrm{C}$. Dos fungos estudados, 64 linhagens $(80 \%)$ apresentaram atividade

Tabela 3. Atividade da celulase de fungos filamentosos isolados do solo da região do Banhado Grande, Estação Ecológica de Juréia-Itatins, SP, cultivados em papel de filtro (FPase) por 14 dias a $28^{\circ} \mathrm{C} \mathrm{e} \mathrm{em} \mathrm{farelo} \mathrm{de} \mathrm{trigo} \mathrm{(CMCase)} \mathrm{por} 4$ dias a $25^{\circ} \mathrm{C}$. $\mathrm{U}=$ unidade de atividade enzimática $\left(\mu \mathrm{mols} \mathrm{mL}^{-1} \mathrm{~min}^{-1}\right) ; \mathrm{U}_{\mathrm{f}}=$ unidades de FPase; $\mathrm{U}_{\mathrm{c}}=$ unidades de CMCase.

Table 3. Cellulase activity of filamentous fungi isolated from soil of the Banhado Grande region, Ecological Station of Juréia-Itatins, SP, cultivated on filter paper (FPase) for 14 days at $28^{\circ} \mathrm{C}$ and wheat bran medium (CMCase) for 4 days at $25^{\circ} \mathrm{C}$. $\mathrm{U}=$ enzymatic activity units $\left(\mu \mathrm{mols} \mathrm{mL}^{-1} \mathrm{~min}^{-1}\right) ; \mathrm{U}_{\mathrm{f}}=$ FPase units; $\mathrm{U}_{\mathrm{c}}=$ CMCase units.

\begin{tabular}{|c|c|c|c|c|c|}
\hline Fungos & $\mathrm{U}_{\mathrm{f}}$ & $\mathrm{U}_{\mathrm{c}}$ & Fungos & $\mathrm{U}_{\mathrm{f}}$ & $\mathrm{U}_{\mathrm{c}}$ \\
\hline Aspergillus niger & 0,018 & 1,01 & Penicillium purpurogenum I & 0,015 & 0,71 \\
\hline Aspergillus wentii & - & 0,55 & Penicillium purpurogenum II & 0,016 & 0,34 \\
\hline Aspergillus sp. & - & 0,72 & Penicillium purpurogenum III & - & 1,09 \\
\hline Chalara paradoxa & 0,015 & 1,03 & Penicillium rugulosum & 0,017 & 0,23 \\
\hline Chaunopycnis alba & - & - & Penicillium sclerotiorum I & 0,017 & 0,47 \\
\hline Chloridium virescens I & 0,018 & 0,36 & Penicillium sclerotiorum II & 0,015 & 0,75 \\
\hline Chloridium virescens II & - & 0,50 & Penicillium sclerotiorum III & 0,016 & 0,51 \\
\hline Cladosporium cladosporioides & - & 0,47 & Penicillium simplicissimum I & 0,017 & 0,78 \\
\hline Colletotrichum sp. & - & 0,11 & Penicillium simplicissimum II & 0,014 & 0,47 \\
\hline Cylindrocladium clavatum & 0,014 & 0,62 & Penicillium simplicissimum III & - & 0,39 \\
\hline Doratomyces stemonitis & - & 0,27 & Penicillium simplicissimum IV & 0,019 & 0,74 \\
\hline Gliocephalotrichum simplex & 0,018 & 0,02 & Penicillium simplicissimum $\mathrm{V}$ & 0,021 & 0,74 \\
\hline Gliocladium nigrovirens & 0,015 & 0,38 & Penicillium spinulosum I & 0,014 & 0,69 \\
\hline Gliocladium roseum I & 0,015 & 0,93 & Penicillium spinulosum II & 0,019 & 0,70 \\
\hline Gliocladium roseum II & 0,015 & 0,10 & Penicillium variabile I & 0,015 & 0,74 \\
\hline Metarhizium anisopliae & - & 0,59 & Penicillium variabile II & 0,015 & 0,12 \\
\hline Mucor hiemalis & 0,014 & 0,53 & Penicillium verruculosum I & 0,016 & 0,49 \\
\hline Myrothecium roridum I & 0,016 & 0,33 & Penicillium verruculosum II & 0,014 & 0,40 \\
\hline Myrothecium roridum II & - & 0,51 & Penicillium sp. & 0,016 & 0,59 \\
\hline Myrothecium roridum III & - & - & Pestalotiopsis pauciseta & 0,019 & 0,72 \\
\hline Paecilomyces carneus I & 0,015 & 0,66 & Scopulariopsis carbonaria & 0,023 & 0,21 \\
\hline Paecilomyces carneus II & 0,016 & 0,49 & Trichoderma hamatum I & 0,015 & 0,95 \\
\hline Paecilomyces carneus III & 0,016 & 0,63 & Trichoderma hamatum II & 0,017 & 0,41 \\
\hline Penicillium aculeatum & 0,015 & 0,18 & Trichoderma harzianum I & 0,016 & 0,67 \\
\hline Penicillium citrinum I & 0,015 & 1,07 & Trichoderma harzianum II & 0,016 & 1,02 \\
\hline Penicillium citrinum II & 0,021 & 0,66 & Trichoderma harzianum III & - & 1,42 \\
\hline Penicillium corylophilum & 0,015 & 0,60 & Trichoderma harzianum IV & 0,014 & 0,40 \\
\hline Penicillium decumbens & 0,021 & 0,18 & Trichoderma harzianum $\mathrm{V}$ & 0,015 & 1,64 \\
\hline Penicillium fellutanum I & 0,017 & 1,00 & Trichoderma harzianum VI & 0,017 & 0,35 \\
\hline Penicillium fellutanum II & - & 0,48 & Trichoderma inhamatum I & 0,019 & 1,32 \\
\hline Penicillium funiculosum & 0,016 & 0,57 & Trichoderma inhamatum II & 0,015 & 1,07 \\
\hline Penicillium glabrum I & 0,015 & 0,56 & Trichoderma koningii I & 0,017 & 0,86 \\
\hline Penicillium glabrum II & 0,016 & 0,59 & Trichoderma koningii II & 0,015 & 0,96 \\
\hline Penicillium herquei & 0,016 & 0,81 & Trichoderma koningii III & 0,016 & 0,06 \\
\hline Penicillium janthinellum & 0,017 & 0,93 & Trichoderma longibrachiatum & 0,018 & 1,42 \\
\hline Penicillium miczynskii & - & 0,79 & Trichoderma pseudokoningii I & 0,015 & 1,10 \\
\hline Penicillium nigricans I & - & 0,49 & Trichoderma pseudokoningii II & 0,014 & 1,45 \\
\hline Penicillium nigricans II & 0,019 & 0,79 & Trichoderma viride I & 0,014 & 1,17 \\
\hline Penicillium nigricans III & 0,020 & 0,71 & Trichoderma viride II & 0,017 & 0,83 \\
\hline Penicillium oxalicum & 0,019 & 0,59 & Verticillium lecanii & 0,016 & 0,51 \\
\hline
\end{tabular}


FPase que variou entre $1,4.10^{-2}$ e $2,3.10^{-2} \mathrm{U}$, sendo o melhor resultado obtido com Scopulariopsis carbonaria.

Resultados com valores superiores foram obtidos por Attili (1994) estudando fungos isolados do solo do Banhado Grande (EEJI) e processados com a mesma metodologia de análise descrita anteriormente. Neste estudo, Aspergillus giganteus apresentou maior valor para a atividade FPase, 7,6.10-2 U. Em outro trabalho, Cenciani (1997) cultivou Gliocladium nigrovirens e Gliocladium roseum I e II, em diferentes meios de cultura e variou as condições de cultivo. Os resultados, porém, foram inferiores aos obtidos no presente estudo.

O cultivo de Aspergillus terreus GN1 em fermentador com capacidade de $10 \mathrm{~L}$, em bagaço de cana-de-açúcar tratado com álcali, proporcionou uma atividade de FPase de 3,2.10-2 U (Garg \& Neelakantan 1982). Quatro linhagens mutantes de Trichoderma reesei cultivadas em diferentes meios de cultura apresentaram resultados que variaram de 3,9 a 16,3 $\mathrm{U}$ (Cochet 1991). Todavia, melhor resultado $\left(18,0 \mathrm{U} \mathrm{mL}^{-1}\right)$ foi verificado com Trichoderma sp. A-001 em meio contendo papel de filtro e $0,2 \%$ do surfactante Tween 80 (Gashe 1992). Observa-se que a atividade da celulase depende, não somente da linhagem, mas das técnicas utilizadas.

Os fungos foram, finalmente, cultivados em meio de farelo de trigo por 4 dias a $25^{\circ} \mathrm{C}$, para verificar a atividade CMCase, que foi evidenciada em 78 linhagens (95\%). As únicas exceções foram as linhagens de Myrothecium roridum III e Chaunopycnis alba que também não apresentaram atividade nos experimentos anteriores (tabelas 1,3). Quatorze linhagens tiveram atividade igual ou superior a uma unidade de atividade CMCase $\mathrm{mL}^{-1} \mathrm{~min}^{-1}$ nas condições do ensaio, sendo Trichoderma harzianum $\mathrm{V}$ aquela que apresentou melhor resultado (1,64 U). Apesar de estudos demonstrarem o potencial das linhagens de Trichoderma na produção de celulases (Cochet 1991, Gashe 1992), e serem algumas espécies usadas intensivamente para a despoluição ambiental pela capacidade de degradarem resíduos e efluentes (Buchert et al. 1993), espécies dos gêneros Aspergillus e Penicillium também têm sido citadas como boas produtoras destas enzimas (Kurasawa et al. 1992, Kuhad \& Singh 1993, Castillo et al. 1994, Kim et al. 1997). O gênero Penicillium, representado por maior número de linhagens aqui estudadas, tem sido constantemente utilizado como fonte de enzimas em vários setores industriais (Carvalho et al. 1992, Teixeira 1994).
Os resultados deste estudo evidenciaram que a produção de celulases depende do tipo de substrato e que o uso de distintos métodos torna difícil a comparação com os resultados obtidos por diferentes autores. Deve-se salientar ainda que os fungos produtores de celulases, na natureza, não ocupam o mesmo nicho ecológico em cultura pura, onde não existe competição; ao contrário, eles interagem com outros organismos celulolíticos e com aqueles que degradam vários polímeros. Essa associação é responsável pela completa mineralização dos substratos celulósicos nos ecossistemas onde estes organismos estão inseridos. Além disso, as linhagens de fungos do solo aqui investigadas foram isoladas em duas áreas com coberturas vegetais distintas e em diferentes estações do ano. Acrescente-se que os meios de cultura e $\mathrm{pHs}$ utilizados para o isolamento também foram diferentes, na tentativa de ampliar a diversidade da micota resultante (Garlipp 1995). Todos esses fatores influenciaram diretamente os resultados obtidos com os diferentes isolados de uma mesma espécie, como por exemplo os apresentados por Trichoderma harzianum I a VI (tabelas 1, 3).

Os resultados aqui obtidos demonstraram que, dentre as linhagens estudadas, não houve nenhuma que se destacasse das demais, quanto ao potencial para produção de atividade da celulase. Todas elas, praticamente, se igualaram. Destaque-se, porém, a importância da realização de estudos futuros para um maior conhecimento sobre a biodiversidade e as funções exercidas por estes microrganismos em ambientes terrestres e de suas interações com fatores bióticos e abióticos dentro de um ecossistema. Sugere-se, que estudos mais detalhados com as linhagens de Trichoderma: T. harzianum III e V, T. inhamatum I, T. longibrachiatum, T. pseudokoningii II e T. viride I, deverão ser realizados, através de outros testes laboratoriais, para verificar melhor o potencial enzimático de tais linhagens.

Agradecimentos - Os autores agradecem à Fapesp pelo auxílio financeiro (Processo 96/7636-0) e pela bolsa de doutorado concedida a Ruegger (Processo 96/07574-5).

\section{Referências bibliográficas}

ATTILI, D.S. 1994. Isolamento, identificação e ecologia de fungos celulolíticos do solo da Estação Ecológica de Juréia-Itatins, SP. Tese de doutorado, Universidade Estadual Paulista, Rio Claro. 
BAYER, E.A. \& LAMED, R. 1992. The cellulose paradox: pollutant par excellence and/or a reclaimable natural resource? Biodegradation 3:171-188.

BUCHERT, J., SALMINEN, J., SIIKA-AHO, M., RANUA, M. \& VIIKARI, L. 1993. The role of Trichoderma reesei xylanase and mannanase in the treatment of softwood kraft pulp prior to leaching. Holzforschung 47:473-478.

CARVALHO, S.M.S., TEIXEIRA, M.F.S., ESPOSITO, E., MACHUCA, A., FERRAZ, A. \& DÚRAN, N. 1992. Fungal screening from decayed Laurel and Cedar trees. Applied Biochemical and Biotechnology 37:150-157.

CASTILLO, M.R., GUTIERREZ-CORREA, M., LINDEN, J.C. \& TENGERDY, R.P. 1994. Mixed culture solid substrate fermentation for cellulolytic enzyme production. Biotechnology Letters 16:967-972.

CENCIANI, K. 1997. Atividade enzimática de espécies do gênero Gliocladium isolado do solo da Estação Ecológica Juréia-Itatins, SP. Monografia, Universidade Federal de São Carlos, São Carlos.

COCHET, N. 1991. Cellulases of Trichoderma reesei: influence of culture conditions upon the enzymatic profile. Enzyme and Microbial Technology 13:104-109.

FELDMAN, K.A., LOVETT, J.S. \& TSAO, G.T. 1988. Isolation of the cellulase enzymes from the termophilic fungus Thermoascus aurantiacus and regulation of enzyme production. Enzyme and Microbial Technology 10:262-272.

GALLIANO, H., GAS, G. \& DURANT, H. 1988. Lignocellulose biodegradation and ligninase excretion by mutant strains of Phanerochaete chrysosporium hyperproducing cellulases. Biotechnology Letters 10:655-660.

GARG, S.K. \& NEELAKANTAN, S. 1982. Bioconversion of sugar cane bagasse for cellulase enzyme and microbial protein production. Journal of Food Technology 17:271-279.

GARLIPP, A.B. 1995. Isolamento e identificação de fungos filamentosos do solo do Banhado Grande, na Estação Ecológica de Juréia-Itatins, SP. Dissertação de mestrado, Universidade Estadual Paulista, Rio Claro.

GASHE, B.A. 1992. Cellulase production and activity by Trichoderma sp. A-001. Journal of Applied Bacteriology 73:79-82.

GRANDI, R.A.P. \& ATTILI, D.S. 1996. Hyphomycetes on Alchornea triplinervia (Spreng.) Müll. Arg. leaf litter from the Ecological Reserve of Juréia-Itatins, State of São Paulo, Brazil. Mycotaxon 60:373-386.

KIM, S.W., KANG, S.W. \& LEE, J.S. 1997. Cellulase and xylanase production by Aspergillus niger KKS in various bioreactors. Bioresource Technology 59:63-67.

KUHAD, R.C. \& SINGH, A. 1993. Enhanced production of cellulases by Penicillium citrinum in solid state fermentation of cellulosic residue. World Journal of Microbiology and Biotechnology 9:100-101.
KURASAWA, T., YACHI, M., SUTO, M., KAMAGATA, Y., TAKAO, S. \& TOMITA, F. 1992. Induction of cellulase by gentiobiose and its sulfur-containing analog in Penicillium purpurogenum. Applied and Environmental Microbiology 58:106-110.

LYNCH, J.M., SLATER, J.H., BENNETT, J.A. \& HARPER, S.H.T. 1981. Cellulase activities of some aerobic microorganisms isolated from soil. Journal of General Microbiology 127:231-236.

MONTENECOURT, B.S. \& EVELEIGH, D.E. 1977. Semiquantitative plate assay for determination of cellulase production by Trichoderma viride. Applied and Environmental Microbiology 33:178-183.

NEIROTTI, E. \& AZEVEDO, J.L. 1988. Técnica semiquantitativa de avaliação da produção de celulases em Humicola sp. Revista de Microbiologia 19:78-81.

NOGUEIRA, E.B.S. \& CAVALCANTI, M.A.Q. 1996. Cellulolytic fungi isolated from processed oats. Revista de Microbiologia 27:7-9.

ORBERG, P.K. 1981. Studies on cellulase production from annual ryegrass straw by Trichoderma reesei. Dissertação de mestrado, Oregon State University, Oregon.

PINTO, I.M.A. 1999. As micotas filamentosas do solo e da água do Rio Una do Prelado, Estação Ecológica de JuréiaItatins, SP. Tese de doutorado, Universidade Estadual Paulista, Rio Claro.

PRADA, G.M. \& PAGNOCCA, F.C. 1997. Ascomycetous yeasts associated with naturally occurring fruits in a tropical rain forest. Folia Microbiologica 42:39-46.

ROBSON, L.M. \& CHAMBLISS, G.H. 1989. Cellulases of bacterial origin. Enzyme and Microbial Technology 11:626-644.

RODRIGUES, E.C. 1987. Caracterização citogenética e bioquímica do fungo celulolítico Humicola sp. Dissertação de mestrado, Universidade de São Paulo, Piracicaba.

TAUK-TORNISIELO, S.M., GIANNOTTI, A.M.D., RUEGGER, M.J.S. \& MALAGUTTI, E.N. 2000. Aphyllophorales from the Atlantic rainforest of the Ecological Station of JuréiaItatins, São Paulo, Brazil. Brazilian Journal of Ecology 4:99-105.

TEATHER, R.M. \& WOOD, P.J. 1982. Use of congo redpolysaccharide interactions in enumeration and characterization of cellulolytic bacteria from the bovine rumen. Applied and Environmental Microbiology 43:777-780.

TEIXEIRA, M.F.S. 1994. Obtenção de espécies de Aspergillus e Penicillium termofílicas e termotolerantes na Amazônia e caracterização de suas enzimas de interesse na indústria de alimentos. Dissertação de mestrado, Universidade Federal do Amazonas, Manaus.

THIEMANN, J.E., XAVIER, M.S.S.P., COLEN, G. \& GUIA, M.M. 1980. Produção de celulases e hidrólise enzimática de resíduos celulósicos. In Fermentações Industriais e Transformações Microbianas no solo (J.S. Furtado, coord.). Sociedade Brasileira de Microbiologia, São Paulo, p.168-185. 